\title{
Evaluation of Faculty Mentoring Practices in Seven U.S. Dental Schools
}

\author{
Thikriat Al-Jewair, Amy Kristina Herbert, V. Leroy Leggitt, Tawana Lee Ware, \\ Maritzabel Hogge, Cynthia Senior, Rebecca K. Carr, John D. Da Silva
}

Abstract: The aim of this cross-sectional study was to examine the faculty mentoring practices in seven dental schools in the U.S. A 34-item survey was administered electronically to dental faculty members of all ranks, tracks, and job categories in seven dental schools using faculty listservs. Survey questions addressed current mentoring practices in which the faculty members were involved; their perceptions of those mentoring practices; their perceived characteristics of an ideal mentoring program, mentor, and mentee; perceived best practices; and respondents' demographics. The survey was conducted from October 2017 to February 2018. A total of 154 surveys were completed (response rate 22\%). Over 58\% (90/154) of the respondents reported receiving no mentoring; $31.9 \%$ (49/154) said they received informal mentoring; and 9.7\% (15/154) received formal mentoring. Of the 64 respondents who received mentoring, both formal and informal, 92.2\% (59/64) were full-time faculty, and 7.8\% (5/64) were part-time faculty $(\mathrm{p}=0.001)$. Approximately $39 \%$ of the respondents indicated that their mentoring program was not overseen by anyone and that participation was voluntary. The top three perceived benefits of mentoring were increased overall professional development, development of a career plan, and increased professional networks. The three most important characteristics of an ideal mentoring program for the respondents were a program based on the needs of the mentee, a mentor who has the desire to help the mentee, and a mentee who is eager to learn. The results of this study showed a very low level of formal or informal faculty mentoring programs in the dental schools surveyed. Future studies are needed to determine best practices and strategies to expand and enhance mentoring of faculty members.

Thikriat Al-Jewair, BDS, MBA, MSc, MS, FRCD(C), is Associate Professor and Graduate Program Director, Department of Orthodontics, School of Dental Medicine, University at Buffalo; Amy Kristina Herbert, DDS, MFA, is Assistant Professor of Pediatric Dentistry, University of Texas School of Dentistry at Houston; V. Leroy Leggitt, DDS, MS, PhD, is Professor and Chair, Department of Orthodontics and Dentofacial Orthopedics, Loma Linda University School of Dentistry; Tawana Lee Ware, DDS, MSD, is Assistant Professor, Department of Pediatric Dentistry, Indiana University School of Dentistry; Maritzabel Hogge, DDS, MS, MSMEd, is Associate Professor and Director of Radiology, Department of Diagnostic Sciences, College of Dental Medicine, Nova Southeastern University; Cynthia Senior, RDH, MEd, is Assistant Professor and Clinic Director, Department of Dental Hygiene, School of Dentistry, University of Mississippi Medical Center; Rebecca K. Carr, MPH, is Senior Evaluator, Community Partnerships \& Access to Care, and Adjunct Assistant Professor, University of New England College of Dental Medicine; and John D. Da Silva, DMD, MPH, ScM, is Vice Dean, Harvard School of Dental Medicine and Medical Director of Harvard Dental Center. Direct correspondence to Dr. Thikriat Al-Jewair, Department of Orthodontics, School of Dental Medicine, University at Buffalo, 140 Squire Hall, 3435 Main Street, Buffalo, NY 14214; thikriat@buffalo.edu.

Keywords: predoctoral dental education, faculty, faculty development, mentoring

Submitted for publication 2/12/19; accepted 6/30/19; first published online 8/12/19

doi: $10.21815 / J D E .019 .136$

$\mathrm{O}$ ral health care professionals who have chosen an academic career entered academia in various ways. Some entered the academic profession directly from training programs, while others have practiced for a period of time and then returned to the university setting. ${ }^{1}$ Among this array of professionals, the common feature is that all are working in a system that is hierarchical, but often without a clear path for academic promotion. ${ }^{2,3}$ Roger et al. reported that, in academic dentistry, junior faculty members found it difficult to navigate the pathways necessary to achieve promotion and/or tenure. ${ }^{3}$ Mid-career educators in the health professions can find their career progress stagnating, with little guidance to help them overcome the next hurdle to full professorship. ${ }^{3,4}$ To address these challenges, mentoring programs have been implemented in university systems to provide guidance and clarity to early and mid-career educators.

Mentoring can have far-reaching impact on the career of a faculty member. Effects have been found to include career and personal development, increased retention rates, the ability to achieve career advancement with promotion and/or tenure status, and improved job satisfaction. ${ }^{2,4-9}$ Mentoring can also provide important emotional support for junior faculty members 
from senior colleagues who have surmounted the same hurdles and can personally relate to them. A systematic review by Sambunjak et al. ${ }^{10}$ updated by Kashiwagi et al. ${ }^{4}$ examined mentoring programs for medical students and physicians. These investigators consistently found that mentoring cannot be overlooked as an important factor when considering an individual's overall personal and career development.

Mentoring is especially important for new educators who often have little knowledge about academic culture and the process necessary to progress in academic ranks. ${ }^{11,12}$ Additionally, they need a guide to learn how to navigate new environments and to become more visible in the academic community. Schrubbe stated that not only do formal mentoring programs have a positive impact on new educators; they can also aid in retaining faculty members. ${ }^{13}$

While mentoring programs can be helpful, many of them are not standardized: they are often informal, and in some instances, faculty members are not even aware of their existence. In a 2008 national study of faculty work environment and satisfaction in dental schools, Haden et al. found that only $25 \%$ of the respondents were aware of a formal mentoring program at their school. ${ }^{2}$ Of those who took advantage of these programs, one in four was dissatisfied with the experience. In a qualitative study of mentoring with 16 faculty members, Jackson et al. found that $98 \%$ of the participants cited "lack of mentoring" as contributing to hindering their career progress. ${ }^{14}$ Those authors recommended that mentorship programs be formalized in institutions.

For many educators, tenure and promotion are two major career advancement goals in which not only mentorship (advising and guiding) but also sponsorship (promoting and highlighting) are sought. ${ }^{2}$ While mentors are available for advice and support, sponsors actively advocate for faculty members regarding particular opportunities that will advance their careers. Ibarra et al. found that, while women received mentorship, they often did not receive the sponsorship that results in promotions. ${ }^{15}$ This lack of sponsorship and advocacy resulted in women more frequently being offered lateral moves in lieu of advancement. In a study of female dental faculty members, Gadbury-Amyot et al. highlighted the distinctive hurdles that female academicians face and the impact this can have on career advancement, including challenges like family obligations and work-life imbalance. ${ }^{16}$

Prior studies have demonstrated the impact of mentoring on faculty members' development. ${ }^{17-19}$
There are, however, only fragmented evidence and examples available on mentoring programs that are designed to support early and mid-career faculty in academic dental settings. Information regarding the utilization and execution of existing mentoring programs in academic dentistry will be an asset to establishing best practices and will aid dental educators nationwide in their career advancement. Through a collaborative effort by seven faculty members who examined their respective programs, this study was developed. The aim of this cross-sectional study was to examine the faculty mentoring practices in seven dental schools in the U.S.

\section{Methods}

The study methods and procedures were approved by the Institutional Review Board at each institution included in the study: Harvard University, University at Buffalo, Loma Linda University, Nova Southeastern University, Indiana University, University of Texas Health Science Center at Houston, and University of New England. Three of the institutions were public, while four were private. In the Carnegie Classification, one was classified as R1 (very high research activity), three as R2 (high research activity), one as M1 (master's colleges and universities: larger programs), and two as special focus four year (medical schools and centers). ${ }^{20}$ This cross-sectional study was conducted from October 2017 to February 2018.

The invitation to participate in the survey was sent to faculty members in all dental disciplines, of all ranks (instructor, assistant professor, associate professor, and full professor), and in all tracks (clinical or non-tenure, tenure, research, innovation, or other). The innovation track indicates being an innovator in clinical approaches, including diagnosis, treatment and prevention, technology applications in clinical care, and model-of-care delivery developments. ${ }^{21}$ Additionally, the invitation included faculty members of any job category (full-time or part-time, including adjunct volunteer faculty). To be considered for inclusion, faculty members needed to be employed for at least one year in the same institution. Faculty members whose background was not in dentistry, other staff members, or those employed for less than one year at their institution were excluded. The estimated sample size was 700 dental faculty members, working in the seven participating dental schools.

A 34-item survey was used in this study. The items were obtained, with permission, from a survey 
developed by Welch et al. ${ }^{22}$ The Welch et al. survey was sent to 135 department chairs to obtain information on faculty mentoring practices in emergency medicine. We modified that survey to apply to a dental setting and to target all faculty members. Items were added to obtain perceptions of the strengths and weaknesses of existing mentoring programs, as well as the perceived need for and benefits of mentoring. The responses to these questions were modeled on the results of Gironda et al. who assessed the impact of a mentoring program on the professional development of clinician-scientists in one dental school. ${ }^{23}$

The 34 survey items were divided into five sections: 1) current mentoring practices, 2) perceptions of current mentoring practices, 3 ) characteristics of an ideal mentoring program, mentor, and mentee, 4) best practices, and 5) demographics. Current mentoring practices included questions on whether the faculty member was being mentored, type of mentoring he or she received (formal: being part of a mentoring program that tracks progress, has measurable outcomes, and requires evaluations; or informal: conducted in an ad hoc manner as needed), location where mentoring occurs, number of mentors, affiliation/s of mentors, mentoring method, involvement of mentee, length of participation, authority overseeing the mentoring, and basis on which pairing with the mentor occurred. Questions about the perceptions of current mentoring practices were focused on likes and dislikes of the mentoring program, perceived benefits, favorite aspects of the program, program's strengths and weaknesses, program's impact on career, and perceived need of a program if one does not exist. Questions were also asked about the characteristics of an ideal mentoring program, mentor, and mentee and willingness to share best practices. Finally, questions on faculty demographics included information about the respondent's gender, experience, rank, track, specialty, highest level of education attained, and research experience prior to entering an academic career. All survey variables were categorical and open-ended for items that had "other" as a response option.

The survey was pilot tested for face and content validity with five full-time faculty members from different dental disciplines. The survey items were then revised and modified accordingly. The revised survey was registered and administered electronically via Research Electronic Data Capture (REDCap, Version 7.3; Vanderbilt University, Nashville, TN, USA) ${ }^{24}$ to faculty listservs in the seven dental schools. The survey was accompanied by a cover letter, explaining the study procedures and the voluntary basis of participation. No compensation was made to subjects for participating in this study. The responses were blinded, and no identifying information about employer, such as name of dental school and academic department, was collected from participants. This feature was designed to limit unit and item non-response bias and to increase the response rate. The survey was sent at three time points to maximize the response rate: $\mathrm{T}_{0}$ (initial sending); $\mathrm{T}_{1}$ (one-week post $\mathrm{T}_{0}$ ); and $\mathrm{T}_{2}$ (two to three weeks post $\mathrm{T}_{1}$ ).

Data were analyzed using the Statistical Package for the Social Sciences software (Version 25 for Windows, IBM Corp., Armonk, NY, USA). Descriptive statistics were calculated for all variables and were reported as frequencies and percentages. Responses to the question "what kind of mentoring are you receiving?" were recoded into "Yes" (formal or informal mentoring) or "No" (none). Age in years was collapsed into four categories: 35 or under; 36-45; 46-60; and over 60. Differences in age by job category were calculated using chi-square test. The presence or absence of a mentoring program was evaluated based on the following variables: employment period, rank, track, job category, tenure status, and highest level of education. Statistical tests were two-tailed and interpreted at the $5 \%$ level of significance.

\section{Results}

A total of 154 surveys were completed (response rate $22 \%$ ). The majority of the respondents $(77.3 \%, 119 / 154)$ were full-time faculty. The remaining $22.7 \%$ (35/154) were part-time faculty. Table 1 shows the age distribution of respondents by job category.

Approximately 37\% (54/148) of the respondents held the rank of assistant professor (Table 2). Among the respondents, $58.7 \%(84 / 143)$ were on a clinical academic track, $12.6 \%(18 / 143)$ were on a tenure track, and $16.1 \%(23 / 143)$ reported an "other" track, such as teaching, academic, or education. When asked about the highest level of education they attained, 49\% (72/147) reported DDS, DMD, or equivalent, while the rest had master's, doctoral, or other advanced degrees.

When asked about current mentoring practices, $41.6 \%(64 / 153)$ of respondents reported receiving mentoring at their school; of those, $76.6 \%(49 / 64)$ reported receiving informal mentoring; and $23.4 \%$ 
Table 1. Age of faculty members in study, by number and percentage of respondents in each job category (full-time $\mathrm{N}=119$, part-time $\mathrm{N}=35$ )

\begin{tabular}{lcc} 
Age Category in Years & Full-Time & Part-Time \\
\hline 35 or under & $11(9.2 \%)$ & $9(25.7 \%)$ \\
$36-45$ & $32(26.9 \%)$ & $6(17.1 \%)$ \\
$46-60$ & $37(31.1 \%)$ & $8(22.9 \%)$ \\
Over 60 & $39(32.8 \%)$ & $12(34.3 \%)$
\end{tabular}

\begin{tabular}{|c|c|c|c|c|}
\hline \multirow[b]{2}{*}{ Variable } & \multirow[b]{2}{*}{ Total } & \multicolumn{2}{|c|}{ Mentoring Program } & \multirow[b]{2}{*}{$\mathrm{p}$-value } \\
\hline & & Yes & No & \\
\hline \multicolumn{4}{|l|}{ Years in academia } & \multirow[t]{6}{*}{0.164} \\
\hline $1-2$ years & $16(10.7 \%)$ & $7(11.0 \%)$ & $9(10.5 \%)$ & \\
\hline $3-5$ years & $21(14.1 \%)$ & $10(15.9 \%)$ & $11(12.8 \%)$ & \\
\hline $6-10$ years & $24(16.1 \%)$ & $13(20.6 \%)$ & $11(12.8 \%)$ & \\
\hline $11-15$ years & $26(17.4 \%)$ & $14(22.2 \%)$ & $12(14.0 \%)$ & \\
\hline$>15$ years & $62(41.6 \%)$ & $19(30.2 \%)$ & $43(50.0 \%)$ & \\
\hline \multicolumn{4}{|l|}{ Academic rank } & \multirow[t]{5}{*}{0.916} \\
\hline Instructor & $19(12.9 \%)$ & $8(12.7 \%)$ & $11(12.9 \%)$ & \\
\hline Assistant professor & $54(36.5 \%)$ & $25(39.7 \%)$ & $29(34.1 \%)$ & \\
\hline Associate professor & $50(33.8 \%)$ & $20(31.7 \%)$ & $30(35.3 \%)$ & \\
\hline Professor & $25(16.9 \%)$ & $10(15.9 \%)$ & $15(17.6 \%)$ & \\
\hline \multicolumn{5}{|l|}{ Academic track } \\
\hline Clinical & $84(58.7 \%)$ & $31(50.0 \%)$ & $53(65.4 \%)$ & \multirow[t]{5}{*}{0.151} \\
\hline Tenure & $18(12.6 \%)$ & $9(14.5 \%)$ & $9(11.1 \%)$ & \\
\hline Research & $12(8.4 \%)$ & $7(11.3 \%)$ & $5(6.2 \%)$ & \\
\hline Innovation & $6(4.2 \%)$ & $5(8.1 \%)$ & $1(1.2 \%)$ & \\
\hline Other (teaching, academic, education) & $23(16.1 \%)$ & $10(16.1 \%)$ & $13(16.0 \%)$ & \\
\hline \multicolumn{5}{|l|}{ Job category } \\
\hline Full-time & $119(77.3 \%)$ & $59(92.2 \%)$ & $60(66.7 \%)$ & \multirow{2}{*}{$0.001^{*}$} \\
\hline Part-time & $35(22.7 \%)$ & $5(7.8 \%)$ & $30(33.3 \%)$ & \\
\hline \multicolumn{4}{|l|}{ Tenure status } & \multirow[t]{3}{*}{0.398} \\
\hline Tenured & $18(12.2 \%)$ & $6(9.5 \%)$ & $12(14.1 \%)$ & \\
\hline Non-tenured & $130(87.8 \%)$ & $57(90.5 \%)$ & $73(85.9 \%)$ & \\
\hline \multicolumn{4}{|l|}{ Highest level of education } & \multirow[t]{5}{*}{0.471} \\
\hline DDS, DMD, or equivalent & $72(49.0 \%)$ & $28(45.2 \%)$ & $44(51.8 \%)$ & \\
\hline MS/MSc & $36(24.5 \%)$ & $15(24.2 \%)$ & $21(24.7 \%)$ & \\
\hline $\mathrm{PhD}$ & $25(17.0 \%)$ & $14(22.6 \%)$ & $11(12.9 \%)$ & \\
\hline Other & $14(9.5 \%)$ & $5(8.1 \%)$ & $9(10.6 \%)$ & \\
\hline \multicolumn{5}{|c|}{ Note: Responses may not total 154 due to no responses. } \\
\hline \multicolumn{5}{|l|}{ *Statistically significant at $5 \%$} \\
\hline
\end{tabular}

$(15 / 64)$ received formal mentoring (Table 3$)$. Of the respondents who received mentoring, both formal and informal, 92.2\% (59/64) were full-time faculty members, and $7.8 \%(5 / 64)$ were part-time faculty members; this difference was significant $(\mathrm{p}=0.001)$.

The primary method of the reported formal and informal mentoring was through one-on-one meetings. Of the respondents, 39.1\% (25/64) reported their mentoring program was not overseen by anyone, and $12.5 \%(8 / 71)$ reported that "other" personnel were overseeing the program-specifically, the associate dean for faculty affairs or development, dean, or a peer mentoring group. More than half $(56.3 \%, 36 / 64)$ of the respondents who were engaged in mentoring programs had two to five mentors, with the majority of mentors being from the same 
Table 3. Current mentoring practices in seven dental schools, by number and percentage of respondents who reported receiving mentoring $(\mathrm{N}=64)$ except as noted

\begin{tabular}{|c|c|}
\hline Variable & Number $(\%)$ \\
\hline \multicolumn{2}{|c|}{ Method of mentoring program received (all respondents, $N=154$ ) } \\
\hline Formal & $15(9.7 \%)$ \\
\hline Informal & $49(31.9 \%)$ \\
\hline None & $90(58.4 \%)$ \\
\hline \multicolumn{2}{|l|}{ Types of FORMAL mentoring receivedt } \\
\hline One-on-one & $15(53.6 \%)$ \\
\hline Group mentoring & $6(21.4 \%)$ \\
\hline Peer mentoring & $5(17.9 \%)$ \\
\hline Electronic mentoring & $1(3.6 \%)$ \\
\hline Other & $1(3.6 \%)$ \\
\hline \multicolumn{2}{|l|}{ Types of INFORMAL mentoring receivedt } \\
\hline One-on-one & $35(56.5 \%)$ \\
\hline Group mentoring & $7(11.3 \%)$ \\
\hline Peer mentoring & $16(25.8 \%)$ \\
\hline Electronic mentoring & $1(1.6 \%)$ \\
\hline Other & $3(4.8 \%)$ \\
\hline \multicolumn{2}{|l|}{ Mentoring program is overseen by } \\
\hline Chair & $11(17.2 \%)$ \\
\hline Vice-chair & $2(3.1 \%)$ \\
\hline Formal committee & $2(3.1 \%)$ \\
\hline Appointed faculty member & $16(25.0 \%)$ \\
\hline No one & $25(39.1 \%)$ \\
\hline Other & $8(12.5 \%)$ \\
\hline \multicolumn{2}{|l|}{ Number of current mentors } \\
\hline 1 & $20(31.3 \%)$ \\
\hline $2-5$ & $36(56.3 \%)$ \\
\hline$>5$ & $6(9.3 \%)$ \\
\hline None & $2(3.1 \%)$ \\
\hline \multicolumn{2}{|l|}{ Mentor(s) affiliation } \\
\hline In the department & $17(26.5 \%)$ \\
\hline From other department in the institution & $41(64.1 \%)$ \\
\hline From an outside institution & $6(9.4 \%)$ \\
\hline \multicolumn{2}{|l|}{ Method for becoming involved in mentoring program } \\
\hline Assigned to mentor & $14(21.9 \%)$ \\
\hline Self-identified & $26(40.6 \%)$ \\
\hline Mixed & $18(28.1 \%)$ \\
\hline Other & $6(9.4 \%)$ \\
\hline \multicolumn{2}{|l|}{ Participation is } \\
\hline Mandatory & $9(14.1 \%)$ \\
\hline Voluntary & $43(67.2 \%)$ \\
\hline Both & $12(18.8 \%)$ \\
\hline \multicolumn{2}{|l|}{ Length of participation in mentoring program } \\
\hline $1-3$ months & $2(3.3 \%)$ \\
\hline 4-6 months & $5(8.2 \%)$ \\
\hline 7-11 months & $2(3.3 \%)$ \\
\hline One year & $11(18.0 \%)$ \\
\hline Two years & $7(11.5 \%)$ \\
\hline Three years or more & $24(39.3 \%)$ \\
\hline I am not currently engaged in a mentoring program & $10(16.4 \%)$ \\
\hline \multicolumn{2}{|l|}{ Mentor-mentee pairing is based on } \\
\hline Research interests & $6(10.5 \%)$ \\
\hline Career niche & $11(19.3 \%)$ \\
\hline Skills or need assessment & $12(21.1 \%)$ \\
\hline Gender & 0 \\
\hline Diversity & $1(1.8 \%)$ \\
\hline Other determined by faculty member & $27(47.4 \%)$ \\
\hline
\end{tabular}

†Multiple responses were allowed on these items. On all other items except where noted, responses may not total 64 due to missing responses. 
department or institution. When asked whether the department and/or the institution presented awards for mentoring faculty, $7.8 \%(5 / 64)$ of respondents reported the existence of a departmental award system for faculty mentoring, and 25\% (16/64) reported the presence of such an award system on the institutional level.

Respondents' attitudes about and perceived outcomes of their current mentoring program are shown in Table 4. A large majority $(84.4 \%$, $54 / 64$ ) of respondents noted receiving benefits from participating in the program, while $7.8 \%(5 / 64)$ reported no benefit and the same percentage $(7.8 \%$, 5/64) said they sometimes received benefits. Approximately one-third $(35.9 \%)$ of respondents reported that the mentoring program influenced their leadership skills and development and provided opportunities for career advancement.

Table 5 shows respondents' perceived benefits and need for a mentoring program. The top three perceived benefits were overall increase in professional development (18.1\%), development of a career plan

\section{Table 4. Attitudes and perceived outcomes of current mentoring program of respondents who reported receiving either formal or informal mentoring, by number and percentage of responses to item}

\begin{tabular}{|c|c|}
\hline Variable & Number $(\%)$ \\
\hline \multicolumn{2}{|l|}{ See benefit in participation (respondents who reported receiving mentoring, $N=64$ ) } \\
\hline Yes & $54(84.4 \%)$ \\
\hline No & $5(7.8 \%)$ \\
\hline Other (e.g., sometimes) & $5(7.8 \%)$ \\
\hline \multicolumn{2}{|l|}{ Favorite aspects of the programt } \\
\hline Mentoring opportunities & $22(13.8 \%)$ \\
\hline Networking with colleagues & $27(17.0 \%)$ \\
\hline Leadership training & $21(13.2 \%)$ \\
\hline Teaching training & $18(11.3 \%)$ \\
\hline Research training & $12(7.5 \%)$ \\
\hline Gaining guidance on navigating academic or institutional environment & $39(24.5 \%)$ \\
\hline Individual or customized programming & $16(10.1 \%)$ \\
\hline Other & $4(2.5 \%)$ \\
\hline \multicolumn{2}{|l|}{ Strengths of the programt } \\
\hline Accessibility to mentor & $33(19.8 \%)$ \\
\hline Flexibility in program & $25(15.0 \%)$ \\
\hline Initial and progressive professional needs assessment utilized & $16(9.6 \%)$ \\
\hline Improved time management skills & $8(4.8 \%)$ \\
\hline Helped me establish a career plan & $33(19.8 \%)$ \\
\hline Increased my productivity in teaching activities & $12(7.2 \%)$ \\
\hline Increased my productivity in research activities & $10(6.0 \%)$ \\
\hline Expanded my professional networks & $25(15.0 \%)$ \\
\hline Other & $5(3.0 \%)$ \\
\hline \multicolumn{2}{|l|}{ Weaknesses of the programt } \\
\hline Lack of protected time for mentees to participate in program & $24(20.7 \%)$ \\
\hline Mentor/s were too busy to dedicate adequate time to mentee & $17(14.7 \%)$ \\
\hline Lack of managing expectations of mentorship relationship & $8(6.9 \%)$ \\
\hline No defined goals or outcomes to mentorship experience & $29(25.0 \%)$ \\
\hline Challenges with priorities between mentor and mentee & $4(3.4 \%)$ \\
\hline Lack of engagement or involvement with department chair & $11(9.5 \%)$ \\
\hline Lack of organization with objectives for mentorship experience & $12(10.3 \%)$ \\
\hline Mentee felt overwhelmed by mentorship experience & $2(1.7 \%)$ \\
\hline Other & $9(7.8 \%)$ \\
\hline \multicolumn{2}{|l|}{ The mentoring program has impacted myt } \\
\hline Teaching & $30(25.6 \%)$ \\
\hline Practice & $10(8.5 \%)$ \\
\hline Research & $20(17.1 \%)$ \\
\hline Leadership: skills, development, opportunities & $42(35.9 \%)$ \\
\hline Funding & $9(7.7 \%)$ \\
\hline None & $6(5.1 \%)$ \\
\hline
\end{tabular}




\begin{tabular}{|c|c|}
\hline Variable & Number $(\%)$ \\
\hline \multicolumn{2}{|l|}{ Perceived need for a mentoring program $(\mathrm{N}=151)$} \\
\hline Yes & $127(84.1 \%)$ \\
\hline No & $22(14.6 \%)$ \\
\hline Other & $2(1.3 \%)$ \\
\hline \multicolumn{2}{|l|}{ Perceived benefits of a mentoring program } \\
\hline Increased teaching activity and/or responsibilities & $79(13.1 \%)$ \\
\hline Increased interest and efforts in research & $81(13.5 \%)$ \\
\hline Increased professional networks & $89(14.8 \%)$ \\
\hline Improved time management skills & $52(8.7 \%)$ \\
\hline Development of a career plan & $101(16.8 \%)$ \\
\hline Improved understanding of promotion and tenure process & $84(14.0 \%)$ \\
\hline Increased professional development overall & $109(18.1 \%)$ \\
\hline Other & $6(1.0 \%)$ \\
\hline \multicolumn{2}{|l|}{ tMultiple responses were allowed on this item. } \\
\hline
\end{tabular}

(16.8\%), and larger professional networks (14.8\%). The most important characteristics reported for a mentoring program were that the program be based on the needs of the mentee, the mentor have the desire to help the mentee, and the mentee be eager to learn (Table 6).

\section{Discussion}

To our knowledge, this was the largest study on faculty mentoring practices conducted in dental schools in the U.S. Despite this scope, only $10 \%$ $(15 / 154)$ of respondents across the seven dental

\begin{tabular}{|c|c|}
\hline Variable & Number $(\%)$ \\
\hline \multicolumn{2}{|l|}{ Most important characteristics of an ideal mentoring program } \\
\hline Flexible & $70(16.4 \%)$ \\
\hline Based on needs of the mentee & $100(23.4 \%)$ \\
\hline Promotes career success of the mentee & $98(22.8 \%)$ \\
\hline Enhances academic performance of the mentee & $80(18.7 \%)$ \\
\hline Organized with well-stated goals and/or outcomes & $75(17.5 \%)$ \\
\hline Other & $5(1.2 \%)$ \\
\hline \multicolumn{2}{|l|}{ Most important characteristics of an ideal mentor } \\
\hline Experienced and knowledgeable & $121(16.2 \%)$ \\
\hline Expert in his/her field & $54(7.2 \%)$ \\
\hline Desire to be helpful and advocate for a mentee & $123(16.4 \%)$ \\
\hline Accessible for the mentee & $111(14.8 \%)$ \\
\hline Excellent communication skills & $79(10.5 \%)$ \\
\hline Connected with a significant network & $48(6.4 \%)$ \\
\hline Able to provide wise counsel and guidance & $109(14.5 \%)$ \\
\hline Supportive and encouraging to the mentee & $105(14.0 \%)$ \\
\hline \multicolumn{2}{|l|}{ Most important characteristics of an ideal mentee } \\
\hline Teachable & $111(18.9 \%)$ \\
\hline Eager to learn & $116(19.8 \%)$ \\
\hline Committed to "doing the work" & $96(16.4 \%)$ \\
\hline Able to accept constructive and/or critical feedback & $115(19.6 \%)$ \\
\hline Focused & $66(11.2 \%)$ \\
\hline Open communication & $83(14.1 \%)$ \\
\hline
\end{tabular}


schools reported that they had participated in a formal mentoring program. This finding highlights the severe need for formal mentoring programs in the schools surveyed and perhaps others as well.

We learned that while $84.1 \%$ of respondents agreed that they needed mentoring during their careers, $58.4 \%$ of them were not part of a mentoring program, either formal or informal. This finding demonstrates the need for these institutions to create opportunities for faculty members to find, connect with, and discuss their career goals with a mentor. Also, we found no statistically significant difference when comparing factors such as rank, education, and years in education. It is interesting to note that both senior and junior faculty members expressed that there is a need for mentoring programs, though we cannot be sure whether they answered these questions in relation to how they felt in the current stage of their careers or in relation to how they felt as junior faculty members, despite the fact that we asked about "current" practices.

The benefit of faculty mentoring has been demonstrated in many health professions programs. The University of North Carolina Eshelman School of Pharmacy is an endowed program that provides mentorship to junior faculty and is specifically designed for those who have chosen a "scholarship intensive career track." ${ }^{25}$ In assisting newly recruited faculty members, the program has four specific goals: assurances that faculty members would have access to resources for growth, be assisted in reaching their full potential with minimal delay, create a supportive community, and be exposed to senior faculty members in their own departments and others. This program maintained that the mentorship provided can be either formal or informal, but in all cases should cover every aspect of academic life. The benefactors provided an honorarium for mentors, which not only demonstrated that the junior faculty was of value but also set a standard of expectation for the quality of participation. In a survey of the participants (ten on tenure track and six on clinical track) after the program, 63\% strongly agreed that they received sufficient guidance and support for their professional development, $75 \%$ strongly agreed that they benefited from interactions with mentors, and $88 \%$ strongly agreed that the mentorship program director provided a positive experience. Likewise, in a review of an academic pediatrics mentorship program for junior faculty members in medical education, the mentoring role included life coaching and career guidance, as well as professional and work-life balance advice. ${ }^{26}$ An overall 95\% (183/193) of participants in this program agreed or strongly agreed that their mentors were accessible, and 85\% (165/193) agreed that they would recommend the program to other junior faculty members.

What faculty members have clearly expressed is not just a desire for mentoring, but a need for mentoring in a challenging academic environment, which can be daunting for newly appointed faculty members. ${ }^{3,4}$ Our study examined the perceived need for mentoring of faculty members in dental schools, and similar to Kohn's findings, ${ }^{25}$ more than $84 \%$ of the respondents indicated a need for a mentoring program. When asked about the type of mentoring, the majority (53.6\% and $56.5 \%$, respectively) of respondents who were engaged in formal and informal mentoring answered that they were involved in one-on-one mentoring, and the minority $(3.6 \%$ and $1.6 \%$, respectively) said they were involved in electronic mentorship. While electronics, email, and video conferencing are becoming more popular, the responses implied that in-person mentoring was used more frequently than electronic mentoring. An area to explore in future studies might be the quality of mentoring with in-person vs. electronic interactions.

The three areas in which junior faculty members need to progress to be considered for promotion are teaching, service, and research. Faculty members are assigned to classrooms, preclinical laboratories, and clinics by their departments; however, they are largely left to explore service and research on their own. Our results showed that participation in a mentoring program impacted the participants' teaching activity/responsibilities $(25.6 \%)$ and research efforts $(17.1 \%)$, and $15 \%$ reported that the mentoring program expanded their professional networks. Interdisciplinary professional networking is often difficult when working in an academic institution with strong departmental delineation. This is another area in which mentoring can be very effective. A small percentage $(14 \%)$ of respondents also noted that participation in a mentoring program improved their understanding of promotion and tenure. This finding aligns with the results of Chen et al., who found that mentees felt more prepared to advance in their careers and had a better understanding of the criteria for advancement. ${ }^{26}$

When we compared factors such as rank, education, job category, and years in education, there was a statistically significant difference between 
responses from full-time and part-time faculty members. We found that part-time faculty members were significantly less likely to be involved in mentoring. There could be several factors at play with regard to this result. First, we did not differentiate the number of hours worked in the part-time faculty population. A faculty member who works one day a week was grouped with a faculty member who may work two or three days a week. It is possible that a faculty member who works one day a week may not have the desire to ascend the academic ladder or become involved in scholarly activities other than teaching. Moreover, part-time faculty members who work two or three days a week may not be allotted the necessary administrative time to conduct meetings; they also may not be able to participate in committees where they can meet other, more senior faculty, and they may not be able to attend workshops and events carried out on days they do not work. The possible fallout from this is that part-time faculty members who work three days or fewer may not be receiving guidance that could motivate them to increase their time commitment and thereby attain more permanent academic positions. Additionally, even though other part-time faculty members who work three or more days are significantly contributing to academia and are more likely to seek promotion, they are not being mentored on how to do so.

Our study also reported weaknesses in the quality of the mentoring experience, the most notable being that there were no defined goals or outcomes, as reported by $25 \%$ of respondents. A junior faculty member needs mentoring, but the mentor may also need mentoring or training on how best to help. While our study did not address training programs for mentors, future studies are warranted to further explore mentor training programs and their outcomes. The presence of a dedicated mentorship program director in the University of North Carolina initiative who is responsible for orchestrating the mentoring experience appears to be an effective strategy to minimize or resolve some of the mentoring barriers identified by our study participants. ${ }^{25}$ These challenges include time availability, lack of organization, and setting realistic expectations. Mentoring experiences can easily become overwhelmed by these obstacles when left to informal means of delivery without centralized management.

In our study, $20.7 \%$ of mentees reported a lack of time to meet with their mentors. Time constraint is a great barrier in academic dentistry, as many faculty members are required to teach and work in clinics in their remaining time. A formal program would ensure time dedicated for the experience. This could be accomplished by scheduling events and luncheons. ${ }^{25}$ A formal schedule would also demonstrate to the department the importance that its faculty receive quality mentoring.

There were some limitations to our study that point to areas that can be improved upon to assess what institutions can do to increase the quality and quantity of mentoring for their faculties. Future studies could include a larger sample size and more detailed demographics. It is possible that the sample in this study may have been overrepresented by respondents from some institutions over the others, which may have skewed the results. Also, in our study, the largest age category of participants was over 60 years. It could be that those answering had more administrative time and were answering retrospectively, as their mentorship relationship was experienced as a junior faculty member. Sending the survey to a larger sample of schools would provide the opportunity to better explore differences in age categories as well as time commitment among part-time faculty members. A future survey could also explore faculty members' concept of mentoring. Educators may perceive any type of advice or even feedback on work performance as representing mentoring. Future studies could also explore more deeply the extent to which faculty members distinguish mentoring (advising and guiding) from sponsoring (highlighting and advocating for colleagues' work and skills).

In another possible limitation, some faculty members may have been receiving both formal and informal mentoring; however, the survey did not capture this information. Thus, we suggest that future studies explore mixed mentoring (receiving both formal and informal mentorship) in depth in order to further investigate whether there are differences in the effectiveness between formal and informal mentoring methods exclusively or if a mixed approach is useful. Also, since the surveys were anonymous, the responses were not categorized into groups representing their institution. Thus, there is no way to connect the viewpoints of the respondents to what is currently practiced at their institutions or to examine if institutions with high research activity have more effective mentoring programs. In the future, particularly with a larger sample size, responses can be linked to each school to allow for a more detailed summary of what each institution practices. 


\section{Conclusion}

In this study, results from seven dental schools indicated a lack of formal and informal mentoring programs in the schools surveyed, in spite of faculty members' recognition of the necessity of mentoring for career growth. Most currently implemented mentoring programs were not overseen by anyone, participation in these programs was voluntary, and mentees were the ones responsible to find and select their own mentor(s). Part-time faculty members were statistically less likely than full-time faculty members to receive the mentorship necessary to move forward in their careers. Institutions should formalize their programs to allow for guaranteed administrative time for participation, clearer goals and expectations, and a more robust mentoring experience all around. Programs with dedicated administrative time carved out can help encourage faculty members to engage in mentorship activities. Additionally, a mentorship program coordinator can guide the mentor-mentee relationship to ensure timely and more frequent meetings. Future studies are warranted to determine best practices.

\section{Acknowledgments}

We thank faculty members in the seven dental schools for their participation in the survey.

\section{REFERENCES}

1. Schenkein HA, Best AM. Factors considered by new faculty in their decision to choose careers in academic dentistry. J Dent Educ 2001;65(9):832-40.

2. Haden NK, Hendricson W, Ranney RR, et al. The quality of dental faculty work-life: report on the 2007 dental school faculty work environment survey. J Dent Educ 2008;72(5):514-31.

3. Roger JM, Wehmeyer MM, Milliner MS. Reflections on academic careers by current dental school faculty. J Dent Educ 2008;72(4):448-57.

4. Kashiwagi DT, Varkey P, Cook DA. Mentoring programs for physicians in academic medicine: a systematic review. Acad Med 2013;88(7):1029-37.

5. Mylona E, Brubaker L, Williams VN, et al. Does formal mentoring for faculty members matter? A survey of clinical faculty members. Med Educ 2016;50(6):670-81.

6. Friedman PK. Mentors: who are they? where are they? do we need them? J Dent Educ 1992;56(8):566-8.

7. Rogers J, Monteiro FM, Nora A. Toward measuring the domains of mentoring. Fam Med 2008;40(4):259-63.

8. Sinkford JC, West JF, Weaver RG, Valachovic RW. Modelling mentoring: early lessons from the W.K. Kellogg/ ADEA minority dental faculty development program. J Dent Educ 2009;73(6):753-63.
9. Froeschle ML, Sinkford JC. Full-time dental faculty perceptions of satisfaction with the academic work environment. J Dent Educ 2009;73(10):1153-70.

10. Sambunjak D, Straus SE, Marusic A. Mentoring in academic medicine: a systematic review. JAMA 2006;296(9):1103-15.

11. Manson SM. Early-stage investigators and institutional interface: importance of organization in the mentoring culture of today's universities. AIDS Behav 2016;20 (Suppl 2):304-10.

12. Fountain J, Newcomer KE. Developing and sustaining effective faculty mentoring programs. JPAE 2016;22: 483-506.

13. Schrubbe KF. Mentorship: a critical component for professional growth and academic success. J Dent Educ 2004;68(3):324-8.

14. Jackson VA, Palepu A, Szalacha L, et al. "Having the right chemistry": a qualitative study of mentoring in academic medicine. Acad Med 2003;78(3):328-34.

15. Ibarra H, Carter NM, Silva C. Why men still get more promotions than women. Harv Bus Rev 2010;88(9):80-5.

16. Gadbury-Amyot CC, Pyle MA, Van Ness CJ, et al. Which way to lean? A national study of women dental faculty members' career aspirations and choices. J Dent Educ 2016;80(12):1392-404.

17. Bagramian RA, Taichman RS, McCauley L, et al. Mentoring of dental and dental hygiene faculty: a case study. J Dent Educ 2011;75(3):291-9.

18. Hempton TJ, Drakos D, Likhari V, et al. Strategies for developing a culture of mentoring in postdoctoral periodontology. J Dent Educ 2008;72(5):577-84.

19. Kula K, Glaros A, Larson B, Tuncay O. Reasons that orthodontic faculty teach and consider leaving teaching. J Dent Educ 2000;64(11):755-62.

20. Carnegie Foundation for the Advancement of Teaching. The Carnegie classification of institutions of higher education. Menlo Park, CA: Carnegie Foundation for the Advancement of Teaching, 2011.

21. Office of Faculty Affairs, Harvard Medical School. The faculty of medicine governance, appointment, and promotion handbook. Dec. 2018, Issue 3, Version 1. At: fa.hms.harvard.edu/files/hmsofa/files/fom_handbook current_issue.dec2018v2.pdf. Accessed 10 May 2019.

22. Welch J, Sawtelle S, Cheng D, et al. Faculty mentoring practices in academic emergency medicine. Acad Emerg Med 2017;24(3):362-70.

23. Gironda MW, Bibb CA, Lefever K, et al. A program to recruit and mentor future academic dentists: successes and challenges. J Dent Educ 2013;77(3):292-9.

24. Harris P, Taylor R, Thielke R, et al. Research electronic data capture (REDCap): a metadata-driven methodology and workflow process for providing translational research informatics support. J Biomed Inform 2009;42:377-81.

25. Kohn H. A mentoring program to help junior faculty members achieve scholarship success. Am J Pharm Educ 2014;78(2):1-6.

26. Chen MM, Sandborg CI, Hudgines L, et al. A multi-faceted mentoring program for junior faculty in academic pediatrics. Teach Learn Med 2016;28(3):320-8. 